\title{
Gerakan Bupolo Magrib Mengaji sebagai Media Aktualisasi Pruralisme
}

\author{
Abdul Latif Wabula, Said Abdurahman Assagaf, Abdi Wael, Idrus Hentihu, Rosita Umanailo, Hamiru Hamiru, Mansyur Nawawi, \\ Sukainap Pulhehe, Mirja Ohoibor, Riki Bugis, Edi Said Ningkeula SP, Muhammad Bula, Lutfi Rumkel, Iskandar Hamid, Irma \\ Magfirah, Siami Prafitriyani, Belinda Sam, Wa Malmia, Syaiful Rachman, Salma Yusuf, M Yusran Zakaria, Samsia Umagusi \\ Universitas Iqra Buru \\ chairulbasrun@gmail.com
}

\begin{abstract}
Abstrak
Tujuan penelitian ini mendapatkan gambaran primer tentang pruralisme yang terbangun antar struktur masyarakat maupun antar pemeluk agama di Kecamatan Namlea dengan mengidentifikasi pelaksanaan program bupolo magrib mengaji. Pendekatan yang dipergunakan dalam penelitian ini menggunakan pendekatan kualitatif dan Jumlah informan yang akan diwawancarai sebanyak 40 orang yang diambil secara purposive dengan pertimbangan responden dianggap sebagai pihak-pihak yang terkait untuk mencapai tujuan penelitian. Penelitian dilakukan di Kecamatan Namlea Kabupaten Buru dengan sampel wilayah adalah Desa Namlea, Desa Jamilu dan Desa Lala. Penelitian ini menggunakan teknik pengumpulan data atau teknik yang menggunakan observasi, wawancara mendalam untuk mendapatkan data kondisi kondisi sosial ekonomi masyarakat, terkait pelaksanaan bupolo magrib mengaji. Teknik analisis yang digunakan dalam penelitian ini adalah analisis data kualitatif mengikuti konsep yang diberikan Miles and Huberman dan Spradley.
\end{abstract}

Keyword: gerakan, masyarakat, mengaji, pruralisme aktualisasi

Kecamatan Namlea merupakan Ibukota Kabupaten Buru terdiri dari 11 desa dan 9 dusun. Luas wilayah Kecamatan Namlea 226,55 $\mathrm{Km}^{2}$ serta yang memiliki jumlah penduduk terbanyak di Kabupaten Buru. Penduduk Kecamatan Namlea menurut data Biro Pusat Statistik tahun 2017 adalah 34.326 jiwa. Jumlah ini bertambah terus setiap tahun dengan laju pertumbuhan penduduk 6,26 persen (Data BPS, 2017). Dengan pertambahan penduduk ini, secara otomatis mengakibatkan semakin tingginya heterogenitas penduduk yang berada di Kecamatan Namlea. Peningkatan kepadatan penduduk yang sedemikian cepat dapat mengakibatkan heterogenitas menjadi sebuah ancaman yang mengganggu proses kehidupan bermasyarakat.

Memahami karakter masyarakat Kabupaten Buru sebagai Karakter masyarakat yang heterogen, konsekuensi sebagai daerah baru, yang memiliki berbagai potensi sumberdaya alam dan karakterisktik masyarakat yang semakin majemuk maka Pemerintah Daerah melalui bagian hukum bersama-sama dengan Kementerian Agama Kabupaten Buru mengkonstruksi sebuah program bertujuan untuk menangkal berbagai pengaruh buruk atau dampak negatif dari perkembangan komunikasi bagi kehidupan bermasyarakat di Kabupaten Buru. Gerakan bupolo magrib mengaji kemudian menjadi paradigma baru untuk pendidikan dan pembelajaran masyarakat di Kabupaten Buru.

Mengoptimalkan waktu maghrib bukanlah hal baru maupun trend popular namun telah ada sebelumnya yaitu dengan mengaji maupun tahlilan atau juga diisi dengan kegiatan ritual-ritual lainnya, namun seiring perkembangan teknologi yang terjadi malah sebaliknya, selepas Maghrib, mulai anak kecil hingga orang tua lebih menyukai duduk di depan TV, memegang remote control sambil bercengkerama hingga larut malam setelah seharian beraktifitas di 
luar rumah. Akibatnya, tradisi mengaji selepas Maghrib yang telah menjadi pondasi bagi terbangunnya pola pikir dan sikap beragama masyarakat mulai kehilangan spiritnya. Masyarakat nampak mulai tercerabut dari akar-akar sosial dan agamanya menuju sebuah potret kehidupan yang gamang dan rentan terhadap perilaku negatif dan merusak moralitas agama (Umanailo, 2017).

Indra (2014) dalam penelitiannya tentang pelaksanaan manajemen program gerakan masyarakat magrib mengaji di provinsi sumatera barat mengemukakan manfaat dari program magrib mengaji adalah membentuk sikap dan perilaku moral masyarakat, membangun rekayasa sosial (social engineering) yang didasarkan pada semangat kearifan lokal dan nilai-nilai spiritual, gerakan magrib mengaji sebagai media untuk membangun ikatan yang kuat dalam rangka membentuk keluarga. Sementara itu, Sapendi (2012) dalam penelitiannya tentang membangun hubungan Sosial lintas agama di sekolah, menjelaskan sekolah sebagai lingkungan pendidikan yang memberikan konteks bagi perkembangan siswa dalam berbagai aspeknya. Lingkungan pendidikan adalah segala sesuatu yang ada di sekolah yang berinteraksi langsung maupun tidak langsung dengan siswa dan dapat merekonsruksi nilai-nilai prulalisme.

Penelitian ini dilakukan berdasarkan preferensi pelaksanaan program magrib mengaji di Kecamatan Namlea sebagai upaya rekayasa sosial dalam aktualisasi pruralisme. Selain itu, penelitian ini bertujuan untuk mendapatkan gambaran primer tentang pruralisme yang terbangun antar struktur masyarakat maupun antar pemeluk agama di Kecamatan Namlea.

Gerakan Maghrib Mengaji adalah semacam gerakan dari Departemen Agama Republik Indonesia yang dicanangkan pada tahun 2013. Gerakan ini dilatarbelakangi oleh jarangnya anak-anak yang mengaji Qur'an pada sekarang, yang dengan harapan ini, diharapkan dapat memotivasi para orang tua untuk menyuruh anaknya salat Maghrib dan mengaji di waktu Maghrib.

Gerakan Bupolo Maghrib Mengaji di Kabupaten Buru yang dipelopori oleh Bupati Ramly Umasugi, S.Pi., MM. menemukan signifikasinya. Program ini merupakan sebuah terobosan di tengah kuatnya arus modernisasi yang menawarkan keindahan duniawi. Secara kontekstual, program ini didasarkan pada sebuah kaedah: al-muhafadzatu 'ala al-qadim al-shalih wa al-akhdzu bi al-jadid al-ashlah (menjaga tradisi lama yang baik dan mengambil gagasan atau kebiasaan baru yang lebih baik).

Dari pelaksanaan program ini, setidaknya bermanfaat untuk: pertama, melestarikan tradisi "mengaji", bertadarrus, serta mengkaji Al-Quran dan ilmu agama, selepas shalat Maghrib dalam rangka meningkatkan kualitas kesalehan individual dan sosial yang ditandai dengan meningkatnya kualitas ketaatan beragama melalui pembiasaan belajar agama. Kedua, membentuk sikap dan perilaku moral masyarakat berdasarkan nilai-nilai Islam yang diukur dari integritas, kejujuran, disiplin dan loyalitas dalam menjalankan ajaran agamanya untuk membendung dampak negative dari modernisasi ilmu pengetahuan dan teknologi informasi. Ketiga, membangun rekayasa sosial (social engineering) yang didasarkan pada semangat kearifan local dan nilai-nilai spiritual sebagai pondasi bagi terciptanya karakter bangsa yang berkeadaban menuju masyarakat madani. Keempat, melahirkan generasi yang kuat, beriman dan bertakwa yang memiliki prinsip dan keteguhan dalam menghadapi tantangan kehidupan modern baik dalam tataran individu, keluarga, masyarakat, maupun bangsa. Kelima, menjadikan program maghrib mengaji sebagai media untuk membangun ikatan yang kuat dalam rangka membentuk keluarga (Umanailo, 2017).

Dalam Kamus Besar Bahasa Indonesia, kata aktualisasi berasal dari kata dasar aktual yang artinya benar-benar ada atau sesungguhnya sehingga kata aktualisasi artinya membuat sesuatu menjadi benar- benar ada, sementara aktualisasi diri menurut Hersinta dan Soepomo (2011) adalah sebuah keadaan dimana seorang manusia telah merasa menjadi dirinya sendiri, mengerjakan sesuatu yang disukainya dengan gembira, dengan hati ikhlas. la tidak lagi menempatkan keberhasilan dari pekerjaannya pada ukuran yang biasanya berlaku, yakni penghasilan yang 
diperoleh dari hasil sebuah kerja, ukurannya menjadi berubah sesuai dengan nilai-nilai kehidupan yang dianut dan difahami oleh dirinya.

Diskursus keagamaan dapat dilacak dari beberapa pendekatan dan sudut pandang; Kebudayaan, normative dan filsafat. Dilihat dari hubungan agama dan kebudayaan Khoirul muqtafa dalam tulisannya tentang hal ihwal relasi agama dan kebudayaan membagi tiga fase ; pertama, fase dimana agama dan kebudayaan dipandang sebagai dua komponen yang sulit dipisahkan antara satu dan lainnya. Sehingga sulit melakukan diferensiasi nilai-nilai agama dan nilai-nilai kebudayaan. Kedua, fase dimana agama dan kebudayaan mulai mengalami diferensiasi struktural, agama dan kebudayaan mulai menjadi institusi tersendiri. Ketiga; fase dimana diferenssiasi agama dan kebudayaan semakin transparan dan mulai ada jarak interaksi keduanya (Rahman, 2014).

Pluralisme berasal dari kata pluralis yang berarti jamak, lebih dari satu, atau pluralizzing sama dengan jumlah yang menunjukkan lebih dari satu, atau lebih dari dua yang mempunyai dualis, sedangkan pluralisme sama dengan keadaan atau paham dalam masyarakat yang majemuk bersangkutan dengan system social politiknya sebagai budaya yang berbeda-beda dalam satu masyarakat. Dalam istilah lain plualisme adalah sama dengan doktrin yang menyatakan bahwa kekuasaan, pemerintahan di suatu Negara harus dibagi bagikan antara berbagai gelombang karyawan dan tidak dibenarkan adanya monopoli suatu golongan.

Keberagaman merupakan sunnatullah yang harus direnungi dan diyakini setiap umat, kesadaran umat beragama menjadi kunci bagi keberlangsungan dalam menjalankan agamanya masing-masing. Setiap agama memiliki substansi kebenaran, dalam filsafat prenial suatu konsep dalam wacana filsafat yang banyak membicarakan hakekat Tuhan sebagai wujud absolut merupakan sumber dari segala sumber wujud. Sehingga semua agama samawi berasal dari wujud yang satu, atau adanya the common vision menghubungkan kembali the man of good dalam realitas eksoterik agama-agama. Disamping itu pluralisme harus dipahami sebagai pertalian sejati kebinnekaan dalam ikatan-ikatan keadaban, bahkan pluralisme adalah suatu keharusan bagi keselamatan manusia, melalui mekanisme dan pengimbangan masing masing pemeluk agama dan menceritakan secara obyektif dan transparan tentang historis agama yang dianutnya (Rahman, 2014).

\section{Referensi}

Hamid, I. (2010). Identifikasi gulma pada areal pertanaman cengkeh Eugenia aromatica) di Desa Nalbessy Kecamatan Leksula Kabupaten Buru Selatan. Agrikan: Jurnal Agribisnis Perikanan, 3(1), 62-71.

Hentihu, Idrus (2007) Analisisi Pemasaran Tanaman Nilam (Pogostemon cablin Benth)( Studi Kasus Desa Pamotan Kecamatan Dampit Kabupaten Malang ). Other thesis, University of Muhammadiyah Malang. diakses tanggal 15 Agustus 2018.

Indra, Delfi. 2014. Pelaksanaan Manajemen Program Gerakan Masyarakat Magrib Mengaji Di Provinsi Sumatera Barat. Jurnal alFikrah, 2 (2); 101-113.

Magfirah, I. (2017). Efektivitas Model Pembelajaran Discovery dengan Setting Kooperatif Ditinjau dari Kemampuan Analogi dan Generalisasi Matematis Siswa Kelas VII MTs Al-Fakhriyah Makassar (Doctoral dissertation, Universitas Negeri Makassar).

Magfirah, I., Rahman, U., \& Sulasteri, S. (2015). Pengaruh Konsep Diri Dan Kebiasaan Belajar Terhadap Hasil Belajar Matematika Siswa Kelas Viii Smp Negeri 6 Bontomatene Kepulauan Selayar. MaPan: Jurnal Matematika dan Pembelajaran, 3(1), 103116.

Nawawi, M., \& Agus Sudaryanto, S. H. (2009). Perkawinan adat sasi dan akibatnya terhadap hukum kekerabatan adat di Desa Debowae Kecamatan Waeapo Kabupaten Buru (Doctoral dissertation, Universitas Gadjah Mada).

Ningkeula, E. S. (2015). Analisis karakteristik metereologi dan morfologis DAS Wai Samal Kecamatan Seram Utara Timur Kobi Kabupaten Maluku Tengah. Agrikan: Jurnal Agribisnis Perikanan, 8(2), 81-91.

Ningkeula, E. S. (2016). Analisis karakteristik morfometri dan hidrologi sebagai ciri karakteristik biogeofisik DAS Wai Samal Kecamatan Seram Utara Timur Kobi Kabupaten Maluku Tengah. Agrikan: Jurnal Agribisnis Perikanan, 9(2), 76-86.

Pulhehe, S. (2001). Tinjauan PP Nomor 10 Tahun 1983 Menurut Hukum Islam (Perkawinan-Perceraian) (Doctoral dissertation, Universitas Airlangga). 
Rahman, M Syaiful. (2014). Islam Dan Pluralisme. Fikrah, 2 (1); 401-418.

Sapendi. (2012). Pendidikan Pluralisme Agama: Membangun Hubungan Sosial Lintas Agama Di Sekolah. Jurnal Khatulistiwa: Journal Of Islamic Studies, 2 (2); 154-172.

Umanailo, M Chairul Basrun, Abdi Wael, Idrus Hentihu, Rosita Umanailo, Hamiru Hamiru, Mansyur Nawawi, Sukainap Pulhehe, et al. 2018. "Gerakan Buru Membaca Sebagai Media Pembelajaran Masyarakat Di Kabupaten Buru." OSF. October 6. doi:10.17605/OSF.IO/AEQVT.

Umanailo, M Chairul Basrun. 2017. "Kajian dan Analisis Sosiologi.” OSF. December 11. doi:10.17605/OSF.IO/PV24F.

Umanailo, M Chairul Basrun. 2017. “Masyarakat Buru Dalam Perspektif Kontemporer.” OSF. December 10. doi:10.17605/OSF.IO/KZGX3.

Umanailo, M Chairul Basrun. 2017. “Mengurai Kemiskinan Di Kabupaten Buru." OSF. November 4. doi:10.17605/OSF.IO/8WDXE.

Umanailo, M Chairul Basrun. 2018. "Ilmu Sosial Budaya Dasar." OSF. March 17. doi:10.17605/OSF.IO/4HPWC.

Umanailo, Rosita (2009) Studi Tentang Struktur Dan Komposisi Hutan Pantai Sendang Biru Malang Selatan. Other Thesis, University Of Muhammadiyah Malang. http://eprints.umm.ac.id/11153/ diakses tanggal 15 Agustus 2018.

Umanailo, Rosita (2013) Implementasi Kebijakan Perum Perhutani Dalam Pengelolaan Sumberdaya Hutan Bersama Masyarakat Sekitar Hutan (Studi Di Wilayah Perum Perhutani Kph Malang). Masters thesis, University of Muhammadiyah Malang. http://eprints.umm.ac.id/30546/ diakses tanggal 15 Agustus 2018.

Zakaria, M. Y. (2017). Karakteristik Penyelesaian Masalah Matematika ditinjau dari Kecenderungan Kepribadian Pada Siswa kelas X SMA Negeri 16 Makassar (Doctoral dissertation, Pascasarjana). 